\title{
Self-reported attributes of traffic accident involvement by female teachers working in Saudi Arabia
}

\author{
H. Al-Ahmadi ${ }^{1}$, M. Al-Sughaiyer ${ }^{1}$, N. Ratrout $^{1}$, K. Al-Ofi ${ }^{1}$, \\ H. Muttlak ${ }^{2}$ \& A. Zeeshan Raza ${ }^{3}$ \\ ${ }^{I}$ Department of Civil Engineering, KFUPM, Dhahran, KSA \\ ${ }^{2}$ Department of Mathematics, KFUPM, Dhahran, KSA \\ ${ }^{3}$ Graduate Student, Department of Civil Engineering, KFUPM, \\ Dhahran, KSA
}

\begin{abstract}
In Saudi Arabia, many newly-graduated female teachers live in the city but have to travel outside the city to get a job. They travel long distances everyday using a variety of vehicles. As they are not permitted to drive, these teachers depend on male drivers to take them to their workplaces. During their trips to work, a large proportion of these teachers are involved in traffic accidents which result in serious injury or death. The aims of the presented paper are to identify the potential factors associated with accidents involving female teachers traveling for work. The results are based on a self-completing questionnaire survey carried out in the Kingdom of Saudi Arabia among a representative sample of female teachers. The possible causes studied include the driver and female traveling attributes, vehicle characteristics and environment. The paper includes the results showing the order of significance of the interactions between accident causing factors along with detailed interpretation and discussion of the data. In conclusion, it was noted that there is an urgent need for improvement of safety standards in different provinces of the Kingdom.

Keywords: female teachers' accidents, multi-way frequency analysis, log-linear modeling.
\end{abstract}




\section{Introduction}

The Kingdom of Saudi Arabia is a large country (over 2.2 million square kilometers), occupying an area approximately the size of Western Europe or onefourth the size of the United States. The distance from Riyadh to Jeddah (on the Red sea) is approximately the same as that from Berlin to London. Possessing an arid and hot climate with some of the earth's harshest terrain, the Kingdom includes features from mountains in the southwest and near the Red Sea to sand dunes in the central and eastern parts of the country. The population of approximately 20 million is scattered throughout the country with major concentrations in several distinct regions.

The primary form of transport in the Kingdom is the motor vehicle as there is little in the form of public transportation available. Unfortunately, the high use of motor vehicles results in an extremely high occurrence of motor vehicle accidents, which inflict an increasing socio-economic cost on Saudi Arabia. Each year millions of people are killed or seriously injured in motor vehicle accidents. In Saudi Arabia, during 1998-1999 more than 4200 people died in traffic accidents and another 31,000 people suffered seriously disabling injuries in more than 264000 traffic accidents (Statistical Yearbook [1]). In fact, traffic accidents are one of the major causes of death in Saudi Arabia. Approximately $10 \%$ of all deaths are because of traffic accidents (Statistical Yearbook [1]). Bener and Jadaan [2] found in their study that road injuries are becoming a public health epidemic in Saudi Arabia. Ofosu et al. [3] showed that relative to other causes of mortality and morbidity, the amount of attention they have received from public health professionals and the scientific community is minuscule. Figure 1 shows a comparison of traffic accident statistics between Saudi Arabia and other countries. It can be noted that the fatality rate is almost three times that of developed countries when taken in terms of vehicle ownership.

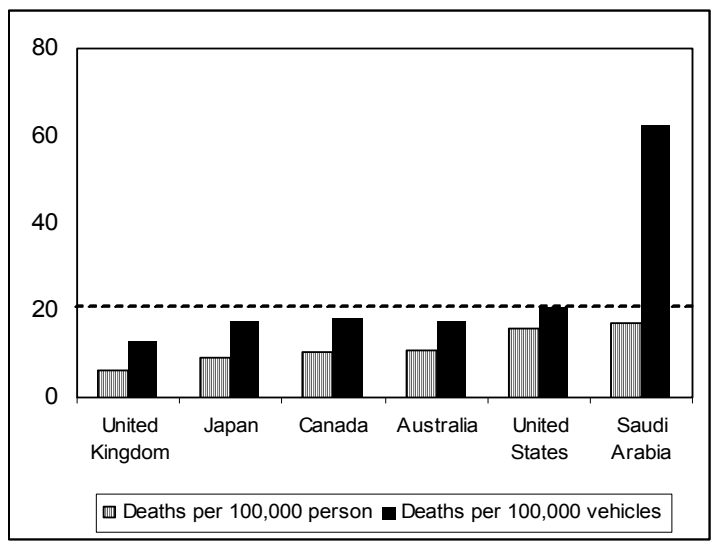

Figure 1: Comparison of traffic accidents statistics between Saudi Arabia and other countries (Abdullah [4]). 
It is within this context that this paper examines one particular group of the Saudi workforce - female teachers who live in one of the main cities but teach in schools located in rural parts of the country. The teachers were chosen as the subject of this study because they form a special group of workers who experience a unique set of problems relating to their travel requirements. The group consists of newly-graduated female teachers who live in the city but who cannot find positions in the inner city due to a lack of available positions. Therefore, the new teachers have to work in schools located in rural areas, which are far from their homes. They start their journey early at dawn in order to travel the long distances and they return at the end of the day exhausted. Some of them travel hundreds of kilometers before reaching their destination. Furthermore, as local customs forbid females from driving, they depend on male drivers to reach their workplace. These teachers have access to a variety of road transportation including passenger car, SUV (sports utility vehicle) called 'suburban' in Saudi Arabia, taxi, bus, or minivan.

Determination of the potential factors related to accidents involving female teachers could be useful to achieving a better understanding of the psychological predictors of accidents. Consequently, the general aim of the study was to test the accident factors interaction, including the following more specific aims:

(1) Investigation of the causes and characteristics of self-reported accidents involving female teachers.

(2) Analysis of the interaction between the involvement of potential factors and frequency of accident occurrence in the last 3 years.

(3) Log-linear modeling of the most likely potential factors in order to find the order of significance.

\section{Methodology}

\subsection{Sample}

To achieve these objectives mail questionnaire surveys were carried out in June 2000. The participants of the survey were a random sample of female teachers selected from 9 provinces of the Kingdom (based on topography), and the response rate was $65 \%(n=1104)$.

\subsection{Questionnaire}

A total of 49 indicators of female teachers' traveling attributes were formulated. Self-reported accident interaction factors included 19 items related to vehicular problems, driver violations, road and weather conditions. Information was also gathered about the travel distance, time, cost and other interacting variables. Teachers were also asked to report the number of accidents and the severity level. A three-level severity range from fatality to no injury was selected. 


\subsection{Statistical analysis}

Log-linear modeling provides a unique way of analyzing discrete data (Tabachnick et al. [5]). Exploratory as well as confirmatory frequency analyses were carried out to examine the structure of the underlying dimensions of both attitudes and accident involvement of the female teachers traveling in the Kingdom during the last 3 years. First a primary analysis was carried out to find the frequencies of the self-reported factors. Then a discrete analysis was carried out using cross tabulation and multi-way frequency analysis. Higher order interactions were analyzed on potential interest, revealed by Multi-way Frequency Analysis (Rencher [6]), by log-linear modeling of the factors (Graham [7]).

Table 1: $\quad$ Causes of accident.

\begin{tabular}{|c|c|c|c|c|}
\hline \multicolumn{2}{|c|}{ Cause of Accident } & \multirow[t]{2}{*}{ Number } & \multirow[t]{2}{*}{$\%$ of Total } & \multirow[t]{2}{*}{ TOTAL } \\
\hline Main & Subset & & & \\
\hline \multirow[t]{7}{*}{ Vehicle } & Tire & 104 & 12.46 & \multirow[b]{7}{*}{30.78} \\
\hline & Steering & 33 & 3.95 & \\
\hline & Lights & 3 & 0.36 & \\
\hline & Brakes & 33 & 3.95 & \\
\hline & Fire in Vehicle & 15 & 1.80 & \\
\hline & Vehicle Age & 46 & 5.51 & \\
\hline & Others & 23 & 2.75 & \\
\hline \multirow[t]{6}{*}{ Driver } & Over Speed & 92 & 11.02 & \multirow[b]{6}{*}{24.79} \\
\hline & Not Obeying Law & 17 & 2.04 & \\
\hline & Reckless Driving & 44 & 5.27 & \\
\hline & Cross on red & 9 & 1.08 & \\
\hline & Fell Asleep & 28 & 3.35 & \\
\hline & Others & 17 & 2.04 & \\
\hline \multirow[t]{4}{*}{ Other } & Other Veh Error & 109 & 13.05 & \multirow[b]{4}{*}{24.55} \\
\hline & Animal Crossing & 59 & 7.07 & \\
\hline & Pedes Crossing & 24 & 2.87 & \\
\hline & Others & 13 & 1.56 & \\
\hline Weather & Bad Weather & 92 & 11.02 & \multirow[b]{3}{*}{19.88} \\
\hline \multirow[t]{3}{*}{ and Road } & Bad Road & 62 & 7.43 & \\
\hline & Other & 12 & 1.44 & \\
\hline & Total & 835 & 100 & \\
\hline
\end{tabular}




\section{Results}

\subsection{Primary analysis}

From primary analysis, mean service life of female teachers was found to be about 5.3 years and the number of years in the current school was found to be 3.8 years. About half of the female teachers use passenger cars to transport them to work and most of the teachers rely on their spouses to drive them. About half of the drivers are Saudi. The percentage frequency of driver age shows that $38 \%$ of the drivers are between ages of 30-40. The analysis for driver ownership shows that $80 \%$ of the drivers own the vehicle. The percentage frequency shows that Japanese vehicles make up $47 \%$ of total. Vehicle occupancy was found to be 5 teachers on average. The statistics also revealed that every teacher travels for 62 minutes (one way) covers a distance of $73 \mathrm{~km}$ (one way) and spends, on average, 681 riyals monthly on their travel.

It was also found that he majority of the female teachers do not have another option of transportation, scoring $72.4 \%$ of the total. Also, most of the respondents have no other option to switch modes of transport, scoring $59 \%$ of the total. The data revealed that about $25 \%$ of the respondents have experienced an accident in the last 3 years, which is quite significant. Table 1 shows the results of the correlation matrix. It can be observed that there exists a strong positive relationship (0.86) between travel distance and travel time. Also the travel cost ties in strongly with travel time and travel distance reaching a value of $(0.73)$ and $(0.75)$ respectively. Various variables of interest were cross-tabulated and correlation was found at p-level 0.05 . It was found that tyre failure, over speeding, other vehicle problems and bad weather remain the major causes of road traffic accidents (RTAs) (see Table 2).

Table 2: $\quad$ Correlation matrix of female teachers travel attributes.

\begin{tabular}{|l|c|c|c|c|c|c|c|c|}
\hline & $\begin{array}{c}\text { No of Yrs } \\
\text { in School }\end{array}$ & $\begin{array}{c}\text { No Of Yrs } \\
\text { in Service }\end{array}$ & $\begin{array}{c}\text { Travel } \\
\text { cost }\end{array}$ & $\begin{array}{c}\text { Model } \\
\text { Year }\end{array}$ & $\begin{array}{c}\text { No of } \\
\text { Teachers }\end{array}$ & Time & Distance & $\begin{array}{c}\text { Acc in } \\
\text { last 3 yrs }\end{array}$ \\
\hline $\begin{array}{l}\text { No of Yrs } \\
\text { in School }\end{array}$ & 1.00 & 0.62 & -0.32 & 0.14 & -0.24 & -0.36 & -0.35 & 0.04 \\
\hline $\begin{array}{l}\text { No Of Yrs in } \\
\text { Service }\end{array}$ & 1.00 & -0.34 & 0.16 & -0.23 & -0.40 & -0.37 & 0.07 \\
\hline Travel cost & 1.00 & -0.20 & 0.19 & $\mathbf{0 . 7 3}$ & $\mathbf{0 . 7 5}$ & -0.16 \\
\hline Model Year & 1.00 & -0.08 & -0.19 & -0.16 & 0.06 \\
\hline No of Teachers & & 1.00 & 0.34 & 0.25 & -0.07 \\
\hline Travel Time & & 1.00 & $\mathbf{0 . 8 6}$ & -0.18 \\
\hline Travel Distance \\
\hline \multicolumn{7}{l|}{ Existence of Traffic accident in last 3 yrs } \\
\hline
\end{tabular}




\section{Accident causation modeling}

\subsection{Model I: relation between driver performance and vehicle condition with respect to having an accident}

Vehicle condition plays a vital role in developing driver performance (Ergun [8]). This model studies the relation between driver performance, vehicle condition and their relation with the number of accidents. A review of k-factor reveals the best model outcome. It was found that there is an improvement in fit when including all 2-way interactions $(\mathrm{k}$-factor $=2)$. The $\mathrm{p}$-value for $\mathrm{k}=3$ was more than 0.01 , the improvement in fit when adding all 3 -way interactions to the model $(\mathrm{k}$-factor $=3$ ) is not significant. The best model will contain some oneway interactions and some two-way interactions having driver performance (A), vehicle condition (B) and the number of accidents (C).

Table 3 shows the results of the marginal and partial association test, which reveal that interaction DRVPERF (Driver Performance) X VEHCOND (Vehicle Condition) is highly significant for both partial and marginal associations. The interaction DRVPERF X ACC (Accident) is also highly significant for both partial and marginal associations. The interaction VEHCOND X ACC is only significant when the marginal association between the two factors is tested $(p$-value $=0.000)$. Partial association is not significant $(p$-value $=0.322176)$.

Table 3: $\quad$ Test of all marginal and partial associations for model I.

\begin{tabular}{|l|c|c|c|c|c|}
\hline & df & $\begin{array}{c}\text { Partial assoc. } \\
\mathrm{X}^{2}\end{array}$ & $\begin{array}{c}\text { Partial assoc. } \\
\mathrm{p}\end{array}$ & $\begin{array}{c}\text { Marginal } \\
\text { assoc. } \\
\mathrm{X}^{2}\end{array}$ & $\begin{array}{c}\text { Marginal } \\
\text { assoc. } \\
\mathrm{p}\end{array}$ \\
\hline $\begin{array}{l}\text { DRVPERF X } \\
\text { VEHCON }\end{array}$ & 16 & 400.633 & 0.000000 & 429.239 & 0.000000 \\
\hline DRVPERF X ACC & 4 & 29.29936 & 0.000007 & 57.90503 & 0.000000 \\
\hline VEHCON X ACC & 4 & 4.676283 & 0.322176 & 33.28149 & 0.000001 \\
\hline
\end{tabular}

From Table 3 it can be concluded that driver performance and vehicle condition are highly correlated and driver performance and the number of accidents are also highly correlated. On the other hand, vehicle condition and the number of accidents are only significant when taken alone. If considered with other factors, they are not significant.

The best interaction based on k-factor and test of marginal and partial associations is DRVPERF X VEHCOND and DRVPERF X ACC (see Table 4).

It is concluded that the major factor associated with accidents involving female teachers in the last 3 years are driver performance and the condition of the vehicle in which the female teacher is traveling. 
Table 4: $\quad$ Evaluation of goodness of fit for model I.

\begin{tabular}{|l|c|c|c|c|c|c|}
\hline \multicolumn{1}{|c|}{ Model I } & $\begin{array}{c}\text { Max. like. } \\
\mathrm{X}^{2}\end{array}$ & $\mathrm{df}$ & $\mathrm{p}$-value & $\begin{array}{c}\text { Pearson } \\
\mathrm{X}^{2}\end{array}$ & $\mathrm{df}$ & $\mathrm{p}$-value \\
\hline $\begin{array}{l}\text { DRVPERF X VEHCON } \\
\text { DRVPERF X ACC }\end{array}$ & 32.557 & 20 & 0.0377 & 32.41803 & 20 & 0.039114 \\
\hline DRVPERF X VEHCON & 299.286 & 25 & 0.000000 & 277.8781 & 25 & 0.000000 \\
\hline DRIVPERF X ACC & 1097.03 & 40 & 0.000000 & 1074.865 & 40 & 0.000000 \\
\hline DRIVPERF & 1363.76 & 45 & 0.00000 & 1631.269 & 45 & 0.000000 \\
\hline VEHCON & 1519.655 & 45 & 0.00000 & 1957.168 & 45 & 0.00000 \\
\hline ACC & 1946.065 & 48 & 0.00000 & 2799.907 & 48 & 0.00000 \\
\hline
\end{tabular}

\subsection{Model II: Relation between driver nationality and driver performance with respect to having an accident}

Model II attempts to study the relation between driver performance, driver nationality and their relation with the number of accidents. It was found that there is an improvement in fit when including all 2-way interactions (k-factor = 2 ). The improvement in fit when adding all 3-way interactions to the model (kfactor $=3$ ) is not significant ( $p$-value $=0.515$ ). The best model will contain some one-way interactions and some two-way interactions of driver nationality (A), driver performance (B) and the number of accidents (C).

Table 5 shows the results for the test of all marginal and partial associations for model II. It is revealed that interaction DRVNAT (Driver Nationality) $\mathrm{X}$ DRVPERF is highly significant for both partial and marginal associations. The interaction DRVPERF X ACC is also highly significant for both partial and marginal associations. The interaction DRVNAT X ACC is not significant for both marginal and partial associations between the two factors.

From Table 5 it can be concluded that driver performance and driver nationality are correlated and driver performance and the number of accidents are also highly correlated. On the other hand, driver nationality and the number of accidents are not related. The best interactions based on k-factor and test of marginal and partial associations are $\mathrm{AB}$ and $\mathrm{BC}$ (see Table 6).

It is concluded that the driver nationality does not relate to the interaction of driver performance and the number of accidents experienced by female teachers in the last 3 years. 
Table 5: $\quad$ Test of all marginal and partial associations for model II.

\begin{tabular}{|l|c|c|c|c|c|}
\hline & $\mathrm{df}$ & $\begin{array}{c}\text { Partial } \\
\text { assoc. } \\
\mathrm{X}^{2}\end{array}$ & $\begin{array}{c}\text { Partial } \\
\text { assoc. } \\
\mathrm{p}\end{array}$ & $\begin{array}{c}\text { Marginal } \\
\text { assoc. } \\
\mathrm{X}^{2}\end{array}$ & $\begin{array}{c}\text { Marginal } \\
\text { assoc. } \\
\mathrm{p}\end{array}$ \\
\hline DRVNAT X DRVPERF & 4 & 9.942768 & 0.041424 & 10.42673 & 0.033841 \\
\hline DRVNAT X ACC & 1 & 0.545083 & 0.460339 & 1.029358 & 0.310317 \\
\hline DRVPERF X ACC & 4 & 18.61088 & 0.000939 & 19.09521 & 0.000755 \\
\hline
\end{tabular}

\subsection{Model III: relation between travel distance and travel time with respect to having an accident}

This model attempts to study the relation between travel distance, travel time and their relation with the number of accidents. Travel distance was categorized into $<30,30-80$ and $>80 \mathrm{~km}$. A review of $\mathrm{k}$-factor was done in order to reveal the best model outcome. It can be observed that there is an improvement in fit when including all 2-way interactions ( $\mathrm{k}$-factor $=2$, p-value $=0.0000$ ). The improvement in fit when adding all 3-way interactions to the model $(\mathrm{k}$-factor $=$ 3 , $\mathrm{p}$-value $=0.24037$ ) is not significant. The best model will contain two-way interactions.

Table 6: $\quad$ Evaluation of goodness of fit for model II.

\begin{tabular}{|l|c|c|c|c|c|c|}
\hline \multicolumn{1}{|c|}{ Model II } & $\begin{array}{c}\text { Max. lik } \\
\mathrm{X}^{2}\end{array}$ & $\mathrm{df}$ & $\mathrm{p}$-value & $\begin{array}{c}\text { Pearson } \\
\mathrm{X}^{2}\end{array}$ & $\mathrm{df}$ & $\mathrm{p}$-value \\
\hline $\begin{array}{l}\text { DRVNAT X DRVPERF } \\
\text { DRVPERF X ACC }\end{array}$ & 3.801 & 5 & 0.578 & 4.142 & 5 & 0.529000 \\
\hline DRVNAT X DRVPERF & 287.6 & 10 & 0.000000 & 268.27 & 10 & 0.000000 \\
\hline DRVPERF X ACC & 317.113 & 10 & 0.000000 & 296.341 & 10 & 0.000000 \\
\hline DRVNAT & 1098.614 & 18 & 0.00000 & 1193.249 & 18 & 0.00000 \\
\hline DRVPERF & 600.912 & 15 & 0.0000 & 663.799 & 15 & 0.00000 \\
\hline ACC & 1136.794 & 18 & 0.00000 & 1284.664 & 18 & 0.00000 \\
\hline
\end{tabular}

Table 7 reveals that interaction TIME (Travel Time) X DISTANCE (Travel Distance) is highly significant for both partial and marginal associations. The interaction DISTANCE X ACC is also significant for both partial and marginal 
associations. The interaction TIME X ACC is also significant for both marginal association and partial association between the two factors.

Table 7: $\quad$ Test of all marginal and partial associations for model III.

\begin{tabular}{|l|l|l|l|l|l|}
\hline & df & $\begin{array}{c}\text { Partial assoc. } \\
\mathrm{X}^{2}\end{array}$ & $\begin{array}{c}\text { Partial } \\
\text { assoc. } \\
\mathrm{p}\end{array}$ & $\begin{array}{c}\text { Marginal. } \\
\text { assoc. } \\
\mathrm{X}^{2}\end{array}$ & $\begin{array}{c}\text { Marginal. ass. } \\
\mathrm{p}\end{array}$ \\
\hline TIME X DISTANCE & 6 & 838.3944702 & 0.00000 & 906.92041 & 0.00000 \\
\hline TIME X ACC & 3 & 10.15029335 & 0.01734 & 78.67627 & $6.19 \mathrm{E}-17$ \\
\hline DISTANCE X ACC & 2 & 15.02361488 & 0.00055 & 83.549438 & $7.61 \mathrm{E}-19$ \\
\hline
\end{tabular}

It can be concluded that travel time and travel distance are correlated and travel distance and the number of accidents are also highly correlated. Travel time and the number of accidents are also correlated. The best interactions based on k-factor and test of marginal and partial associations are TIME $\mathrm{X}$ DISTANCE, DISTANCE X ACC and TIME X ACC (see Table 8).

Table 8: $\quad$ Evaluation of goodness of fit for model III.

\begin{tabular}{|l|c|c|c|c|c|c|}
\hline \multicolumn{1}{|c|}{ Model III } & $\begin{array}{c}\text { max. lik } \\
\text { chi }\end{array}$ & df & p-value & $\begin{array}{c}\text { Pearson } \\
\text { chi }\end{array}$ & df & p-value \\
\hline $\begin{array}{l}\text { TIME X DISTANCE + DISTANCE X } \\
\text { ACC + TIME X ACC }\end{array}$ & 7.4296 & 6 & 0.2829 & 8.0066 & 6 & 0.23764 \\
\hline $\begin{array}{l}\text { TIME X DISTANCE + TIME X } \\
\text { ACCIDENT }\end{array}$ & 22.456 & 8 & 0.00414 & 22.553 & 8 & 0.003996 \\
\hline $\begin{array}{l}\text { TIME X DISTANCE + DISTANCE } \\
\text { X ACC }\end{array}$ & 17.583 & 9 & 0.0403 & 20.437 & 9 & 0.01542 \\
\hline TIME X ACC + DISTANCE X ACC & 845.827 & 12 & 0.0000 & 869.435 & 12 & 0.00000 \\
\hline TIME X DISTANCE & 428.0179 & 12 & 0.0000 & 374.142 & 12 & 0.00000 \\
\hline TIME X ACC & 997.1185 & 16 & 0.0000 & 963.549 & 16 & 0.00000 \\
\hline DISTANCE X ACC & 1165.817 & 18 & 0.0000 & 1180.168 & 18 & 0.00000 \\
\hline TIME & 1402.680 & 20 & 0.0000 & 1779.243 & 20 & 0.00000 \\
\hline DISTANCE & 1576.251 & 21 & 0.0000 & 2112.013 & 21 & 0.00000 \\
\hline ACC & 1317.108 & 22 & 0.0000 & 1631.346 & 22 & 0.00000 \\
\hline
\end{tabular}

It is concluded that the time spent in traveling and distance traveled by female teachers during their work trips are associated with the number of accidents in the last 3 years.

\subsection{Model IV: relation between driver performance and travel distance with respect to having an accident}

In this model the relation between driver performance, travel distance and its relation with the number of accidents was sought. It was found that there is improvement in fit when including all 2-way interactions $(\mathrm{k}$-factor $=2, \mathrm{p}$-value $=$ 
0.0000). The improvement in fit when adding all 3-way interactions to the model ( $\mathrm{k}$-factor $=3, \mathrm{p}$-value $=0.27564$ ) is not significant. The best model will contain some two-way interactions.

Table 9 reveals that interaction DRVPERF $X$ DISTANCE is highly significant for both partial and marginal associations. The interaction DISTANCE X ACC is also significant for both partial and marginal associations. The interaction DRVPERF $\mathrm{X} A C C$ is also significant for both marginal association and partial association between the two factors.

Table 9: $\quad$ Test of all marginal and partial associations for model IV.

\begin{tabular}{|l|c|c|c|c|c|}
\hline & $\mathrm{df}$ & $\begin{array}{c}\text { Partial } \\
\text { assoc. } \\
\mathrm{X} 2\end{array}$ & $\begin{array}{c}\text { Partial } \\
\text { assoc. } \\
\mathrm{p}\end{array}$ & $\begin{array}{c}\text { Marginal. } \\
\text { assoc. } \\
\mathrm{X} 2\end{array}$ & $\begin{array}{c}\text { Marginal } \\
\text { assoc. } \\
\mathrm{p}\end{array}$ \\
\hline DRVPERF X DISTANCE & 4 & 51.12 & 0.000000 & 63.15 & 0.000000 \\
\hline DRVPERF X ACC & 2 & 17.90 & 0.000130 & 29.93 & 0.000000 \\
\hline DISTANCE X ACC & 2 & 23.16 & 0.000009 & 35.19 & 0.000000 \\
\hline
\end{tabular}

It can be concluded that driver performance and travel distance are correlated and travel distance and the number of accidents are also highly correlated. Driver performance and the number of accidents are also correlated. The best interactions based on k-factor and test of marginal and partial associations are DRVPERF X DISTANCE, DISTANCE X ACC and DRVPERF X ACC (see Table 10).

Table 10: $\quad$ Evaluation of goodness of fit for model IV.

\begin{tabular}{|l|c|c|c|c|c|c|}
\hline \multicolumn{1}{|c|}{ Model IV } & $\begin{array}{c}\text { Max. lik } \\
\mathrm{X}^{2}\end{array}$ & $\mathrm{df}$ & $\mathrm{p}$-value & $\begin{array}{c}\text { Pearson } \\
\mathrm{X}^{2}\end{array}$ & $\mathrm{df}$ & $\mathrm{p}$-value \\
\hline $\begin{array}{l}\text { DRVPERF X DISTANCE + } \\
\text { DISTANCE X ACC + DRVPERF X } \\
\text { ACC }\end{array}$ & 5.1159 & 4 & 0.27500 & 5.2828 & 4 & 0.2595 \\
\hline $\begin{array}{l}\text { DRVPERF X DISTANCE + } \\
\text { DRVPERF X ACC X DISTANCE + }\end{array}$ & 28.274 & 6 & 0.00008 & 28.1400 & 6 & 0.00008 \\
\hline $\begin{array}{l}\text { DRVPERF X } \\
\text { DISTANCE X ACC }\end{array}$ & 23.017 & 6 & 0.00022 & 26.00113 & 6 & 0.00022 \\
\hline $\begin{array}{l}\text { DRVPERF X ACC + DISTANCE X } \\
\text { ACC }\end{array}$ & 56.238 & 8 & 0.00000 & 55.56300 & 8 & 0.00000 \\
\hline DRVPERF X DISTANCE & 340.056 & 9 & 0.00000 & 311.4620 & 9 & 0.00000 \\
\hline DRVPERF X ACC & 148.984 & 12 & 0.00000 & 153.5810 & 12 & 0.00000 \\
\hline DISTANCE X ACC & 1081.364 & 12 & 0.00000 & 1081.542 & 12 & 0.00000 \\
\hline DRVPERF & 460.766 & 15 & 0.00000 & 520.717 & 15 & 0.00000 \\
\hline DISTANCE & 1398.403 & 15 & 0.00000 & 1848.63 & 15 & 0.00000 \\
\hline ACC & 1174.11 & 16 & 0.00000 & 1387.906 & 16 & 0.00000 \\
\hline
\end{tabular}


It can be concluded that there is an association between driver performance and distance traveled by the female teachers with the number of accidents experienced in the last 3 years.

\section{Conclusion}

The purpose of this study was to investigate the attributes of work trips taken by female teachers and their involvement in accidents in the last 3 years. The results support the assumption that there are different aspects of travel attributes, as well as different interactions among these attributes. This research relied on a questionnaire method because police records of accidents did not mention whether a female teacher was the occupant of a vehicle involved in an accident. Descriptive statistics, multi-way frequency tables and log-linear models were developed for the data set received.

It was found that there are a number of factors associated with accidents involving female teachers in the last 3 years. Most teachers are involved in accidents while traveling more than $80 \mathrm{~km}$. Captive teachers experience more accidents as do drivers who do not own the vehicle. Most accidents are caused by Asian drivers. Also, drivers of company vehicles are more involved in accidents, and drivers of age $<30$ and $>50$ show poor compliance to traffic safety laws. There are also associations between the number of accidents and: driver performance and the condition of the vehicle; driver performance and travel cost; the time spent traveling and the distance traveled; driver performance and distance traveled.

On the other hand, teachers traveling in buses or passenger cars experience fewer accidents as do teachers traveling with their spouse. Furthermore, driver performance and driver nationality and are not related to the number of accidents.

This research shows the there is an urgent need for driver education programs and enforcement of traffic laws. The attempts to change attributes of female teachers' travel would offer a potential method of bringing about captivity reduction, and the data suggest that specific attributes related to mode of travel, vehicle occupancy and teacher residence could positively be the focus of interventions aimed at changing future accident potential.

\section{Acknowledgements}

The data used in this research project was collected during a research study supported by the King Abdulaziz City for Science and Technology (Al-Ahmadi et al. [9]), whose support is gratefully acknowledged. The authors also wish to thank the King Fahd University of Petroleum and Minerals for the support provided for this work. 


\section{References}

[1] Statistical Yearbook, Kingdom of Saudi Arabia, Ministry of Planning, Central Department of Statistics, 36th issue 1420/ 1421A.H. 2000 AD, 2000.

[2] Bener A., and Jadaan KS. A perspective on road fatalities in Jeddah, Saudi Arabia. Accident Analysis and Prevention, 24(2), pp. 143-148, 1992.

[3] Ofosu, J.B., Aabouammoh, A. M., Bener, A., A study of road traffic accidents in Saudi Arabia. Accident Analysis and Prevention, 20, pp. 95-101, 1988.

[4] Abdullah A.M., Saudi Arabia ministry of communications and its role in improving traffic safety. ITE Journal, pp. 46-50, June 2000.

[5] Tabachnick, B.G. et al., Multivariate Analysis of Variance and Covariance. Using Multivariate Statistics, Fourth Edition, pp. 322-390, 2001.

[6] Rencher A.C., Multivariate Analysis of Variance, Multivariate Statistical Inference and Applications, pp. 121-200, 1998.

[7] Graham, J.U., The Analysis of Cross Tabulated Data, University of Essex, 1977.

[8] Ergun G., Condition of vehicles in Saudi Arabia. Accident Analysis and Prevention, 19, pp. 343-358, 1988.

[9] Al-Ahmadi H.M., Ratrout N., Al-Ofi K., Al-Sughaiyer M., "Accident for female teachers and students traveling in rural areas in Saudi Arabia," Final Report submitted to KACST, July, 2002. 